\title{
GEOPHYSICAL AND UAV-BASED OBSERVATIONS OVER A FLOOD DEFENSE STRUCTURE : APPLICATION TO THE POLDER2C'S EXPERIMENTAL DIKE
}

\author{
R. Antoine ${ }^{1,}$, C. Fauchard ${ }^{1}$, V. Guilbert ${ }^{1}$, B. Beaucamp ${ }^{1}$, C. Ledun ${ }^{1}$, C. Heinkele ${ }^{1}$, L. Saussaye ${ }^{2}$, \\ S. Muylaert ${ }^{3}$, W. Vancalster ${ }^{3}$, D. Depreiter ${ }^{3}$, P. Sergent $^{4}$ \\ ${ }^{1}$ ENDSUM Research Team, Cerema, France \\ ${ }^{2}$ Hydraulic, Geotechnical infrastructure and Geohazard Team, Cerema, France \\ ${ }^{3}$ Vlaanderen, Department of Mobility and Public Works, Belgium \\ ${ }^{4}$ HA Research Team, Cerema, France
}

Commission III, WG 6

KEY WORDS: Electrical Resistivity Tomography, Ground Penetrating Radar, Remote Sensing, UAV

\section{ABSTRACT}

We present geophysical and remote sensing measurements on a flood dike, in the framework of the Polder2C's Interreg European Project (https://polder2cs.eu/). Electrical Resistivity Tomography (ERT) and Ground Penetrating Radar (GPR) profiles have been performed alongside and across the dike. The geophysical measurements are then combined with a Digital Terrain Model (DTM) caarried out with a RGB visible camera on board an Unmanned Aerial Vehicle (UAV). Integrated $3 \mathrm{D}$ results enrich data interpretation and form the basis for Polder2C's future experiments.

\section{INTRODUCTION}

Monitoring flood protection systems has become crucial with the increase of extreme weather events. In this context, geophysical methods such as ERT, GPR, Multichannel Analysis of Surface Waves (MASW), seismic refraction, electromagnetic induction (EMI) or Self Potentials (SP) has gained more and more importance to characterize dikes (Fargier et al., 2014; Tomecka-Suchoń, 2019; Niederleithinger et al., 2012; Rahimi et al., 2018; Bolève et al., 2012). Amongst these methods, ERT and GPR are useful and complementary tools, easy to carried out on the field for dike assessment (Golebiowski, Tomislaw et al., 2020). Most of the cases, they are performed both on crest and at toe of dikes and less often transversely to the structures. In this case, conventional 2D or 3D imaging techniques are mainly applied to relatively flat surfaces (Dahlin, 1996; Fargier et al., 2014), due to the lack of adequate high resolution topographic information. As a consequence, geophysical results are rarely presented as fully integrated within their textured study environment on flood defense systems. Along with these developments for subsurface characterization, optical cameras on-board UAVs has been increasingly used to provide 3D models in the visible domain for routine studies or for mapping flooded areas (Antoine et al., 2020; Feng et al., 2015; Popescu et al., 2017). To date, the combination or the fusion of subsurface information and UAV-based data is still sparse on dikes, while 3D topography is particularly important, especially for ERT or electromagnetic inversion (Günther et al., 2006; Fargier et al., 2014). In this work, we propose a 3D model of the Living Lab Hedwige Prosper Polder (LLHPP) dike, combining ERT and GPR methods and a RGB textured model. The dike was originally built to protect the area from high tides. The
Polder2C's Interreg project now offers a special approach in the development of flood resilience measures at LLHPP. The depoldering of Hedwige-Prosperpolder represents a $6 \mathrm{~km} 2$ living lab environment, where current and innovative techniques, processes, methods and products can be tested for practical validation. First, after a presentation of the study site, the geophysical and remote sensing surveys are exposed. Second, the methodology used for the combination of both surface and subsurface methods is explained. Finally, preliminary results combining ERT, GPR and a 3D RGB textured data of the dike are shown and discussed.

\section{LOCATION OF THE SURVEY}

\subsection{Living Lab Hedwige-Prosperpolder flood defence structure}

The survey was carried out at the LLHPP, located near Antwerp (Belgium) at the Belgium-Netherlands border and took place in August and October 2020 (figure 1).

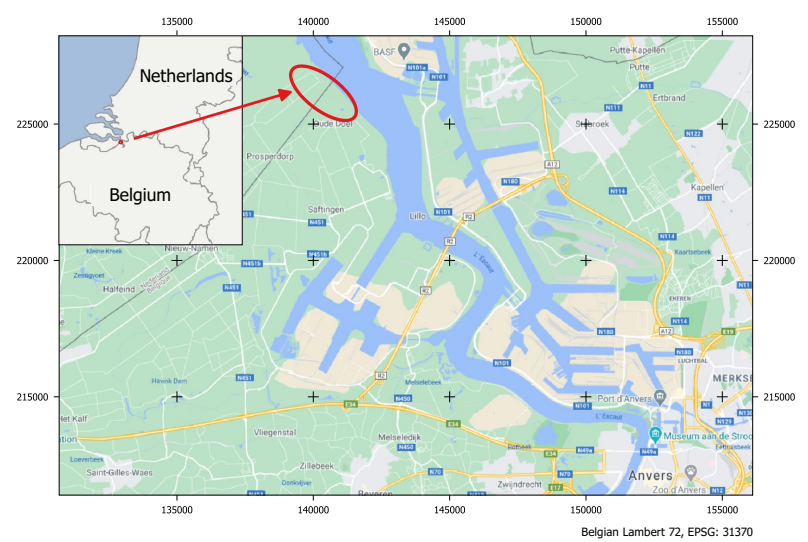

Figure 1. Location of the study site.

The area has been divided into 11 sections for various experiments during the project. Four sections, namely section IV, VI, $\mathrm{X}$ and XI were performed with geophysical methods. A global aerial view of the site with measurement points, profiles and relevant sections numbers is given in the figure 2 .

\footnotetext{
* Corresponding author
} 


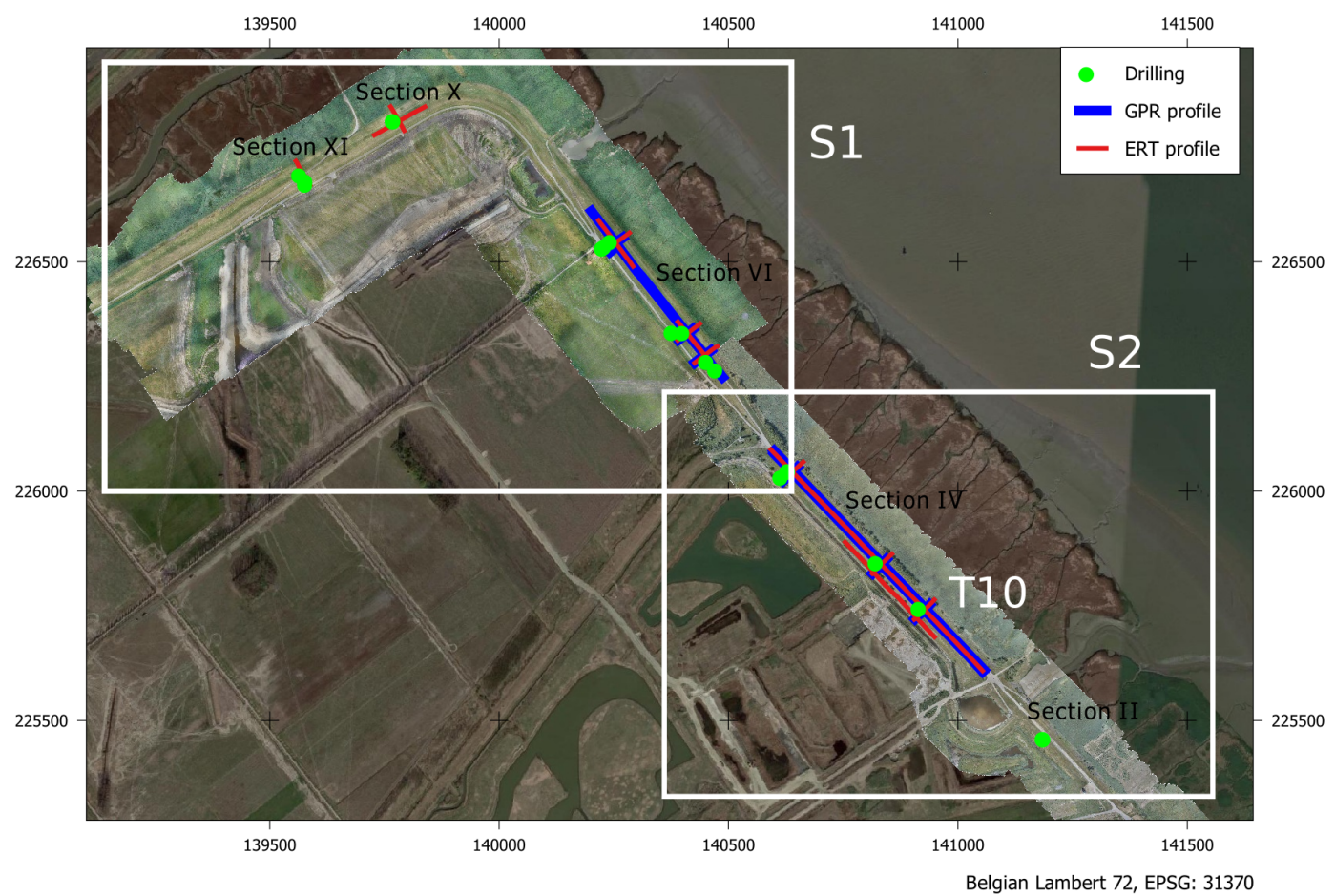

Figure 2. ERT and GPR profiles overlaid with the UAV-based high resolution orthophoto and Google data. White squares indicate the location of both S1 and S2 UAV surveys.

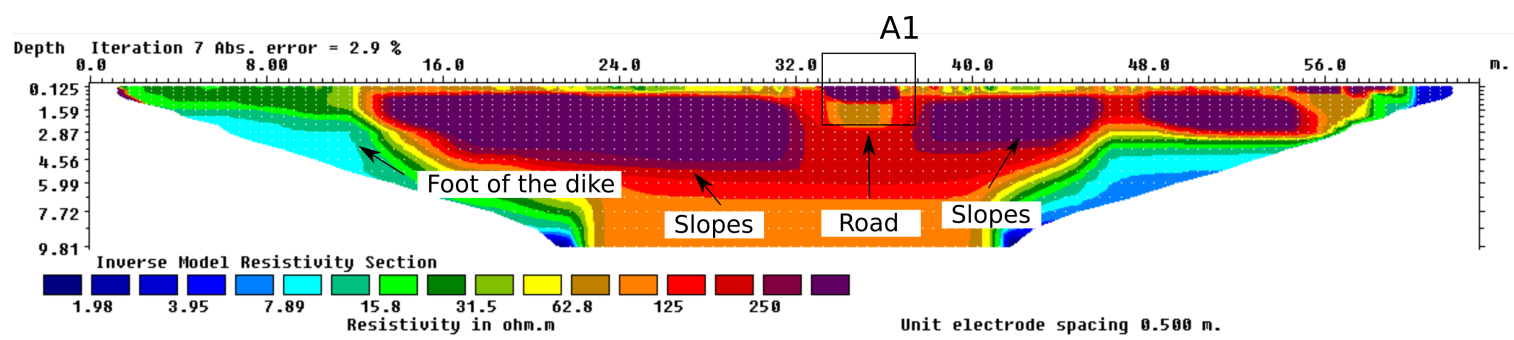

Figure 3. Example of the T10 transverse ERT profile (section IV) displayed without topography. The A1 label refers to the signal associated to the road.

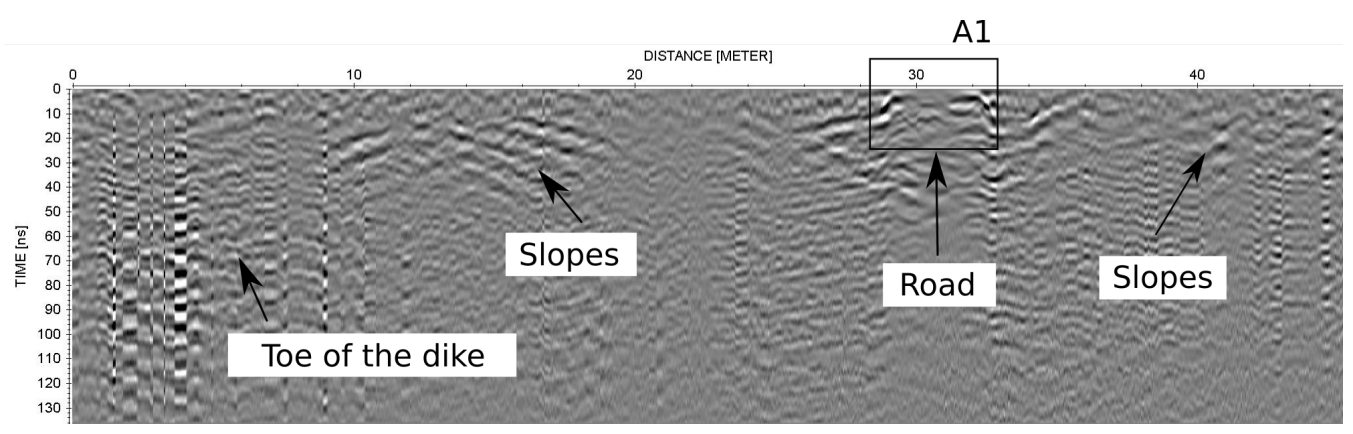

Figure 4. Example of the radargram done along the T10 profile (section IV) and displayed without topography. The A1 label refers to signal associated to the road. 


\section{METHODOLOGY}

\subsection{UAV Remote Sensing}

The UAV survey consists in acquiring RGB images using a digital camera on board a drone above the dike. Images are captured at regular intervals according to a flight plan calculated using the Pix4D application. Thirty Ground Control Points (GCP's) visible from the UAV are placed on the dike and then geo-referenced on the field with a Global Navigation Satellite System. The survey has been divided in two sections ( $\mathrm{S} 1$ and $\mathrm{S} 2$ ) of dimension $\mathrm{d} \approx 500 \mathrm{~m}$ and performed in August 2020 (figure 2). Both longitudinal and transverse flight plans were carried out, at an altitude of $86 \mathrm{~m}$ and $54 \mathrm{~m}$, for the $\mathrm{S} 1$ and $\mathrm{S} 2$ area, respectively. Main survey characteristics are displayed in the table 1 . The processing is performed using the Metashape photogrammetric software, according to the following workflow :

- Georeferencing of the different GCP's seen in the different images;

- Finding tie points on images and retrieval of camera positions. At this stage, a sparse point cloud is available;

- Calculation of dense point cloud from the sparse point cloud;

- Meshing of the dense point cloud;

- Generation of a Digital Elevation Model/Digital Terrain Model and an orthophoto.

For the $\mathrm{S} 1$ section, the error calculated by Metashape after the camera calibration is $3 \mathrm{~cm}, 3.7 \mathrm{~cm}$ and $2.7 \mathrm{~cm}$ in the $\mathrm{x}, \mathrm{y}$ and $\mathrm{z}$ directions, respectively (total error of $5.5 \mathrm{~cm}$, projection error of $0.415 \mathrm{px}$ ). For the $\mathrm{S} 2$ section, this error is $0.9 \mathrm{~cm}, 1 \mathrm{~cm}$ and $1.1 \mathrm{~cm}$ in the $\mathrm{x}, \mathrm{y}$, and $\mathrm{z}$ directions, respectively (total error of $1.7 \mathrm{~cm}$, projection error of $0.361 \mathrm{px}$ ).

\begin{tabular}{|ccccc|}
\hline Section & Camera & Images & Res. & Err. \\
\hline \hline S1 & Sony RX1R II $(35 \mathrm{~mm})$ & 1455 & $1.1 \mathrm{~cm}$ & $5.5 \mathrm{~cm}$ \\
S2 & Yuneek E90 $(8 \mathrm{~mm})$ & 5800 & $1.2 \mathrm{~cm}$ & $1.7 \mathrm{~cm}$ \\
\hline
\end{tabular}

Table 1. UAV survey characteristics, model resolution (Res.) and total error calculated during the modelling (Err.)

\subsection{Electrical Resistivity Tomography}

The ERT method provides information on the electrical resistivity distribution of materials into the ground, related to subsurface lithology and hydrogeological conditions (Zhdanov and Keller, 1994). Five longitudinal and eight transverse profiles have been performed with a Terrameter LS2, a set of cables and inox electrodes and using a Schlumberger protocol (figure 2 ). The spacing between each electrode was 0.5 meter in the transverse direction and 2 and 3 meter in the longitudinal direction. During the survey, we used a Trimble GPS in order to locate profiles. Accurate positioning is ensured in the laboratory thanks to a post-processing based on referenced bas stations. GPS points are recorded at each slope break to obtain a relevant geometry of the dike. Electric data processing includes forward and inverse modelling and leads to the resistivity distribution map using the ORES2DINV software (Loke, 2002). The maximum depth of investigation is $28 \mathrm{~m}$ for the longest profile and $9.6 \mathrm{~m}$ for transverse profiles.
An example of ERT pseudo-section without topographic correction in the T10 transverse direction of section IV is given in the figure 3. Main characteristics of resistivity distribution can be assessed (road, resistive materials at the slopes, conductive substratum, ...), the lack of topography induces some bias during the forward and inverse electric modelling, that may generate in turn artefacts and affect the location of electric anomalies within the dike (Fargier, 2011). Finally, the absence of geometry may also render the ERT results difficult to interpret for non specialist people, leading to a misunderstanding of the method.

\subsection{Ground Penetrating Radar}

The GPR allows to image the subsurface, through the analyze of electromagnetic (EM) waves reflected/diffracted by dielectric contrasts encountered by EM waves into the soil. A groundcoupled bow-tie antenna of $200 \mathrm{MHz}$ has been used to record eight GPR profiles on sections IV and VI. As for the ERT, each profile is located using a GNSS device. Classical data GPR processing was performed thanks to the OReflexW software, including static correction, low-pass filtering, gain function and background removal. The maximum depth of investigation is $\approx 5-6 \mathrm{~m}$. An example of radargram carried out along the T10 profile is shown in the figure 4 without topographic correction. Here again, the principal reflectors can be observed and linked to the different parts of the dike.

\subsection{Combination of ERT, GPR and DTM}

ERT and GPR methods are usually carried out in both transverse and longitudinal directions dikes. These measurements are of paramount importance to detect heterogeneous materials, weathered areas, voids, high clay content zones or preferential fluid flow inside the dike. In most cases, geophysical profile coordinates are recorded with help of GNSS system. However, data accuracy can be affected by environment conditions (presence of trees, complex topography, lack of satellites,...). Consequently, when combined with available DTMs or DEMs, geophysical data may not be properly located. In ares with complex topography, this discrepancy may reach up to several meters in the $\mathrm{z}$ direction and can significantly affect dimension and depth of anomalies. As an example, the figure 5 shows a qualitative view of the difference between 17 GPS measurements (red squares) and the UAV-based DTM for the T10 profile of section IV (snapshot taken from the @CloudCompare open source software). In this case, the maximum error between GPS data and the DTM is $1 \mathrm{~m}$ in the $\mathrm{z}$ direction, while the spacing between each electrode is $1 \mathrm{~m}$.

To overcome this problem, our methodology consists in manually moving each GPS position as close as possible to the DTM, using the Point List Picking tool available in CloudCompare. Then, a Python code re-calculates the right spacing between each electrode position (every $1 \mathrm{~m}$ in the T10 example) along the new path on the DTM, using a linear interpolation. The new profile is then exported for ERT inversion and GPR processing. The RES2DINV software allows the inversion of electrical data using the GNSS positioning ( $\mathrm{x}, \mathrm{y}, \mathrm{z}$ positions) of each electrode. The result is then exported in the Visualisation Tool Kit (VTK) format, one of the native format of the CParaview open source software. Radargrams are exported from the ReflexW software in ASCII format. A Python script is used to generate these images by following the topography of the DTM. Finally, the Cloud Compare open-source software allows to mesh and export GPR results using the VTK format. 


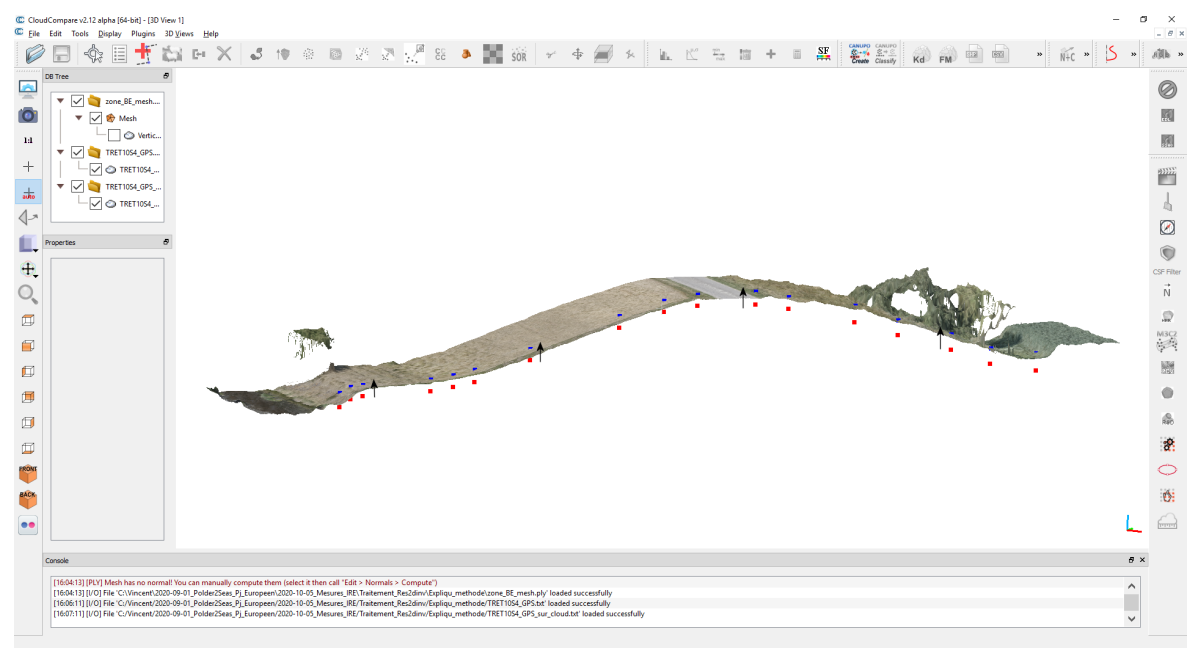

Figure 5. Snapshot of the 17 GPS points (red squares) and UAV-based DTM for the T10 profile as seen within CloudCompare. GPS points are manually corrected in the vertical direction (black arrow), to be as close as possible to the DTM using the Point List Picking Tool in CloudCompare (corrected positions are labelled by blue squares).

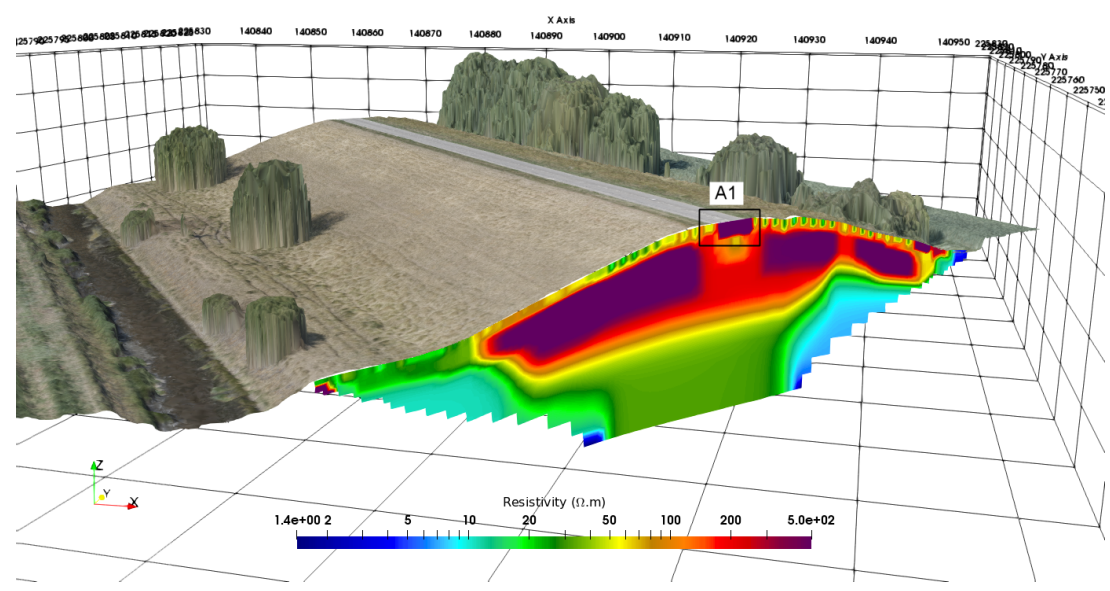

Figure 6. Combined DTM and ERT profile along the T10 profile (see figure 3).

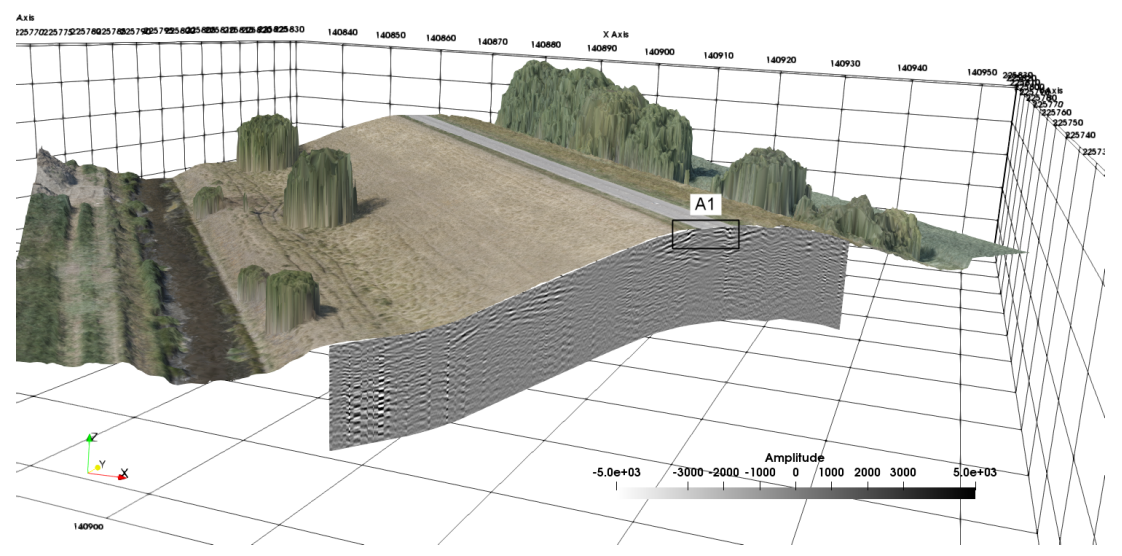

Figure 7. Combined DTM and GPR profile along the T10 profile (see figure 4). 


\section{RESULTS}

Figures 6 and 7 present ERT and GPR results of T10 profile and integrated within a textured environment, displayed thanks to the Paraview software. The 2D electric inversion takes into account the profile topography, leading to a more realistic location of the resistivity distribution compared to the case without topography (Fargier, 2011). As for the ERT, the radargram is deformed following the dike topography. Various reflectors are well located, as observed on the A1 road area. The 3D model also shows some strong reflectors at mid slope within the flank and down to the dike foot, where coaser materials can be present, potentially corresponding to weathered or high porosity areas.

Over the $\approx 500 \mathrm{~m}$ of section IV, the extension of the dike body is clearly detected (figures 6 and 9), with high resistive signal (up to $500 \Omega \mathrm{m}$ ). It may correspond to the presence of dry unconsolidated (silty ?) materials. This deposit lies above a more conductive substratum in depth (clayey soil and/or water-saturated zone). Resistive heterogeneities can be observed along the dike and may be precisely located using the figure 9.

In the same way, the figure 8 provides radargrams realized in transverse and longitudinal directions. It give some useful information about the structure of the soil and an example of anomalies encountered on the field: first, well defined reflectors within the slope show that the flank seems to be composed of coarser materials with potentially higher porosity than the crest. Second, several anomalies corresponding (i) to the presence of a concrete slab located close to stairs at the crest (A2 anomaly), (ii) to the presence of an animal burrow at mid slope within the flank, potentially associated to a more permeable area inside the dike (A3 anomaly) and (iii) to the presence of the road at the dike toe (A4).

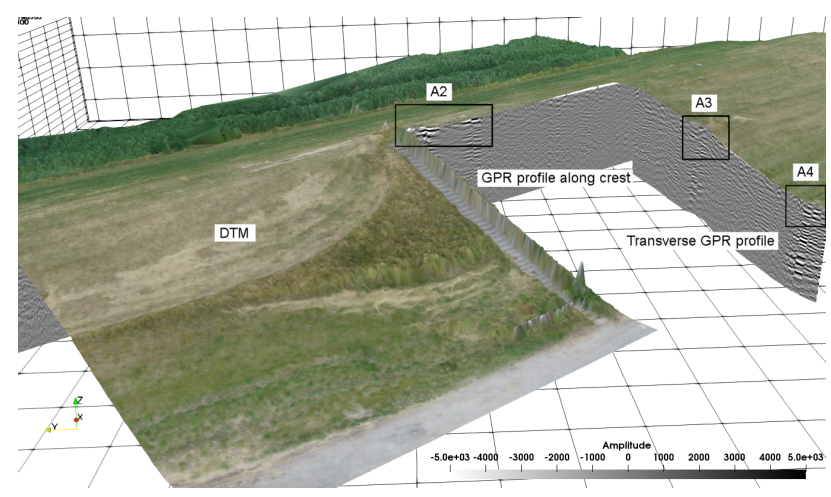

Figure 8. Combined DTM and GPR profiles on section XI.

Although preliminary, the results show the potential of the combination of two independent geophysical methods giving information on resistivity and dielectric permittivity contrasts with a DTM. It offers a powerful tool to interpret a large amount of data in terms of surface mapping and subsurface characterization. Note that we have presented 2D electric modelling, combined with a textured model. Future work will be dedicated to $3 \mathrm{D}$ inverse modelling, taking into account the whole coordinates of the DTM and using the new PymERI inversion code developed in our laboratory (Antoine et al., n.d.).

\section{CONCLUSION AND PERSPECTIVES}

ERT and GPR surveys were conducted on an experimental dike and combined with UAV-based 3D RGB data, leading to a relevant model allowing to easily locate ERT and GPR results. Moreover, data interpretation is easier and enhanced by the addition of surface information given by UAV survey. Finally, it helps to democratize geophysical and remote sensing methods as very useful and cost-effective tools for stakeholders. This study is one of the first step performed in the framework of the Polder2C's project. Geophysical analysis would be improved with recent geotechnical and hydraulic surveys.

One of the major challenges of merging data from very different sensors is the relative location of the data. Indeed, the accuracy of the location is different for each of the sensors, which requires work to bring it all together in a common reference frame. The density of the point clouds is not the same either and it is important to ensure that the information provided by each of the sensors is correctly located. A lot of manual registration is currently done in the point clouds, but several numerical methods are being studied to address this issue as accurately as possible.

\section{ACKNOWLEDGEMENT}

This project is founded by the Interreg 2 Seas Program for the 2019-2022 period. 


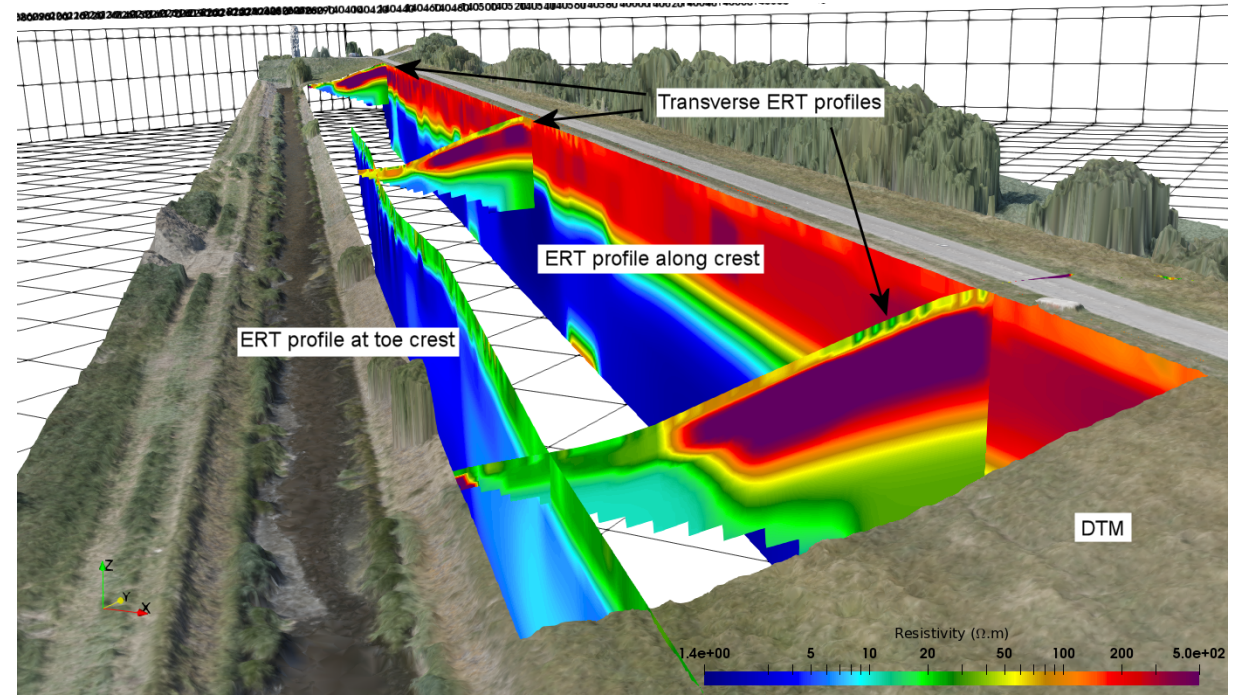

Figure 9. Global view of the combined DTM and longitudinal/transverse ERT profiles on section IV.

\section{References}

Antoine, R., Ciotir, I., Costa, S., Fargier, Y., Fauchard, C., Gout, C., Le Guyader, C., Maquaire, O., Taoum, S., Tonnoir, A., n.d. Coastline erosion study via uav drone remote sensing using python modelling electrical resistivity imaging (pymeri) IGARSS 2020-2020 IEEE International Geoscience and Remote Sensing Symposium, IEEE, 441-444.

Antoine, R., Lopez, T., Tanguy, M., Lissak, C., Gailler, L., Labazuy, P., Fauchard, C., 2020. Geoscientists in the Sky: Unmanned Aerial Vehicles Responding to Geohazards. Surveys in Geophysics, 41(6), 1285-1321.

Bolève, A., Vandemeulebrouck, J., Grangeon, J., 2012. Dyke leakage localization and hydraulic permeability estimation through self-potential and hydro-acoustic measurements: Self-potential 'abacus' diagram for hydraulic permeability estimation and uncertainty computation. Journal of Applied Geophysics, 86, 17-28.

Dahlin, T., 1996. 2D resistivity surveying for environmental and engineering applications. First break, 14(7).

Fargier, Y., 2011. Développement de l'Imagerie de Résistivité Électrique pour la reconnaissance et la surveillance des Ouvrages Hydrauliques en Terre. $\mathrm{PhD}$ thesis, Ecole Centrale de Nantes (ECN).

Fargier, Y., Lopes, S. P., Fauchard, C., François, D., Côte, P., 2014. DC-electrical resistivity imaging for embankment dike investigation: a 3D extended normalisation approach. Journal of Applied Geophysics, 103, 245-256.

Feng, Q., Liu, J., Gong, J., 2015. Urban Flood Mapping Based on Unmanned Aerial Vehicle Remote Sensing and Random Forest Classifier-A Case of Yuyao, China. Water, 7(4), 1437-1455. https://www.mdpi.com/2073-4441/7/4/1437.

Golebiowski, Tomislaw, Piwakowski, Bogdan, 'Cwiklik, Michal, 2020. Application of the GPR and ERT methods for non-invasive examination of a flood dike. MATEC Web Conf., 322, 01010. https://doi.org/10.1051/matecconf/202032201010.
Günther, T., Rücker, C., Spitzer, K., 2006. Three-dimensional modelling and inversion of DC resistivity data incorporating topography-II. Inversion. Geophysical Journal International, 166(2), 506-517.

Loke, M., 2002. RES2DINV ver. 3.50. Rapid 2-D resistivity and IP inversion using the least square method.

Niederleithinger, E., Weller, A., Lewis, R., 2012. Evaluation of geophysical techniques for dike inspection. Journal of Environmental and Engineering Geophysics, 17(4), 185-195.

Popescu, D., Ichim, L., Stoican, F., 2017. Unmanned Aerial Vehicle Systems for Remote Estimation of Flooded Areas Based on Complex Image Processing. Sensors, 17(3). https://www.mdpi.com/1424-8220/17/3/446.

Rahimi, S., Wood, C. M., Coker, F., Moody, T., BernhardtBarry, M., Kouchaki, B. M., 2018. The combined use of MASW and resistivity surveys for levee assessment: A case study of the Melvin Price Reach of the Wood River Levee. Engineering Geology, 241, 11-24.

Tomecka-Suchoń, S., 2019. Ground penetrating radar use in flood prevention. Acta Geophysica, 67(6), 1955-1965.

Zhdanov, M. S., Keller, G. V., 1994. The geoelectrical methods in geophysical exploration. Methods in geochemistry and geophysics, elsevier edn, Elsevier. 